\title{
Medical device related pressure injuries in COVID-19 patients followed up in an intensive care unit
}

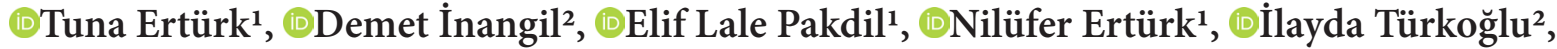 \\ ๑Derdiye Şendir ${ }^{2}$, ๑Berna Dinçer ${ }^{3}$, ๑Hatice Erdoğan ${ }^{4}$, ๑) Füsun Afşar ${ }^{1}$, ๑Ayşın Ersoy ${ }^{1}$ \\ ${ }^{1}$ University of Health Sciences, Sultan 2. Abdulhamid Han Training And Research Hospital, Department of Anesthesiology, İstanbul, Turkey \\ ${ }^{2}$ University of Health Sciences, Hamidiye Faculty of Nursing, İstanbul, Turkey \\ ${ }^{3}$ İstanbul Medeniyet University, Faculty of Health Sciences, Department of Nursing, İstanbul, Turkey \\ ${ }^{4}$ İstanbul Maltepe University, School of Nursing, İstanbul, Turkey
}

Cite this article as: Ertürk T, İnangil D, Pakdil EL, et al. Medical device related pressure injuries in COVID-19 patients followed up in an intensive care unit. J Health Sci Med 2022; 5(1): 227-233.

\begin{abstract}
Aim: The aim of this study is to determine the prevalence of medical device-related pressure injuries in COVID-19 patients.

Material and Method: This study was conducted with a cross-sectional and retrospective design. The data of 436 patients who were followed up and treated in the Anesthesia and Reanimation Intensive Care Unit with the diagnosis of COVID-19 disease between 11.03.2020-31.02.2021 in a Training and Research Hospital in İstanbul were included in the study. The sample of the study consisted of 32 patients out of 436 patients who met the sampling criteria. The data obtained by retrospective reviewing of the patient records were analyzed through the "Patient Information Form" and "Pressure Injury Stage" forms.

Results: Medical device-related pressure injury developed in 32 (7.3\%) of 436 patients examined in the study on the specified dates. $90.6 \%$ of these patients were male, and the average age was $67.5 .43 .7 \%$ had comorbid diseases. According to the Braden Risk Assessment Scale, $25 \%$ of these patients had medium and $71.8 \%$ high risk. Medical devices that cause pressure injury were continuous positive airway pressure mask $(n=13)$, intubation tube $(n=7)$, nasogastric tube $(n=5)$, nasal cannula $(n=3)$, gel pads $(\mathrm{n}=3)$, and oxygen mask $(\mathrm{n}=1)$.

Conclusion: In this study, the potential factors in the study that may have led to the incidence of medical device-related pressure injury specific to COVID-19 disease include the rapid increase in the need for respiratory support, ischemia caused by this infection, and the use of prone position.
\end{abstract}

Keywords: Pressure injury, respiratory support, prone position, intensive care

\section{INTRODUCTION}

Pressure injury is localized damage to the skin and/ or subcutaneous soft tissue caused by the application of intense or prolonged pressure. Pressure injury is usually seen in tissues exposed to anatomical pressure in areas where the individual remains motionless, but it can also occur due to medical or other devices (1). Medical device-related pressure injuries are considered an important health problem for healthcare areas and are called hospital-acquired pressure injuries. Medical device-related pressure injuries occur when the skin or underlying tissues are exposed to constant pressure or shear from medical devices (1-3). All medical devices can potentially cause pressure injuries (4). Medical device-related pressure injuries generally occur around or below medical devices, taking the shape of the devices $(2,5)$. Patients using medical devices are twice as likely to develop pressure injuries than patients who do not use medical devices (6). Medical devicerelated pressure injuries have been reported to account for more than $30 \%$ of all hospital-acquired pressure injuries $(2,7)$.

It is known that acute respiratory failure develops in approximately $5 \%$ of patients infected with the COVID-19 disease caused by the coronavirus called SARS-CoV-2 and they need to be hospitalized in intensive care units (8). It has been described that the majority of these patients are over 60 years of age and have comorbidities such as hypertension, diabetes, 
heart disease and obesity (9). All these factors pose a risk for the formation of pressure injuries. Besides, the increased need for respiratory support devices during intensive care treatment of COVID-19 disease becomes an important risk factor for pressure injuries caused by these devices (5-8). International and national guidelines such as the European Pressure Ulcer Advisory Panel (EPUAP), Wound Ostomy Continence Nursing (WOCN), National Pressure Injury Advisory Panel (NPIAP) have described care practices for pressure injuries related to medical devices, especially those associated with noninvasive respiratory support and pressure injuries related to the prone position (1012).

The rates of intubation and mechanical ventilation among COVID-19 patients admitted to intensive care units have been reported as $71 \%$ to $90 \%$ (13). According to the studies examining medical device-related pressure injuries in these patients, these injuries may develop in the nasal and chin region, especially in patients receiving oxygen therapy with noninvasive respiratory support, and in the facial region connected to the intubation tube in patients who remain in the prone position for a long time $(2,8,14)$.

A thorough examination of the evidence for pressure injury is essential in preventing pressure injuries. Observational studies including the incidence of medical device-related pressure injury, individual factors and care practices play an active role in ensuring patient safety. There are, however, limited studies on the prevalence of medical device-related pressure injuries. The aim of this study is to determine the prevalence of medical device-related pressure injuries in COVID-19 patients.

\section{MATERIAL AND METHOD}

The study was carried out with the permission of University of Health Sciences, Hamidiye Clinical Researchs Ethics Committee (Date: 22.03.2021, Decision No: 21717). The study was conducted in compliance with the "Ethical principles for medical research involving human subjects" of the Helsinki Declaration.

This research was carried out with a cross-sectional and retrospective design. The data of 436 patients who were followed up and treated in the intensive care units of an anesthesia clinic with the diagnosis of COVID-19 between 11.03.2020 and 31.02.2021 in a training and research hospital in İstanbul were included in the study.

As inclusion criteria, the sample consisted of patients aged 18 years and over, who received respiratory support with low flow/high flow oxygen therapy or invasive/ noninvasive mechanical ventilation, and who were reported to have developed medical device-related pressure injuries by wound care nurses. The individual and disease-related characteristics of 32 patients who met these criteria were examined for medical devicerelated pressure injury.

\section{Data Collection Tools and Data Collection}

Patients who received additional respiratory therapy in the intensive care unit from the first patient admitted to the hospital with the diagnosis of COVID-19 until the end of the year were identified. The data obtained by the retrospective scanning of patient files were examined through the "Patient Information Form" and "Pressure Injury Stage" form.

\section{Patient Information Form}

The form includes data on the individual and diseaserelated characteristics of pressure injury and the nursing care given for medical device-related pressure injury in line with the literature reviewed by the researchers (8-14). It covers the individual characteristics of the patients such as age, gender and body mass index (BMI). Among the features related to the disease are data such as respiratory support type, comorbid diseases such as diabetes mellitus (DM), hypertension, peripheral vasculopathy, pressure injury risk level according to Braden Risk Assessment Scale, date of onset of the pressure injury, injury sites.

\section{Braden Risk Assessment Scale}

The risk of pressure injury in the study was determined by the Braden Risk Assessment Scale. The scale was developed by Bergstorm et al. (16) with consideration to the pressure injury risk factors of patients and its Turkish validity and reliability were established by Oğuz and Olgun (Brad), The scale includes six risk factors: stimulus perception, humidity, activity, movement, nutrition, friction-irritation. Except for friction and shear, each variable is scored between 1 and 4 . By summing the subdimension scores of the scale, a total score ranging from at least 6 to 23 is obtained. A total score of 12 points and below are considered as high risk, 13-14 points as risk, and $15-16$ points as low risk.

\section{Pressure Injury Stage Form}

The stage of pressure injuries was evaluated according to the National Pressure Injury Advisory Panel (NPIAP) (17) (Table 1).

\section{Data Analysis}

Frequency and percentage descriptive statistics were used as methods of analysis, and categorical data analyzes were used for individual characteristics. 
Table 1. Pressure Injury Stages (NPIAP) 17

Stage 1 Pressure Injury: Non-blanchable erythema of intact skin Intact skin with a localized area of non-blanchable erythema, which may appear differently in darkly pigmented skin.

Stage 2 Pressure Injury: Partial-thickness skin loss with exposed dermis Partial-thickness loss of skin with exposed dermis. The wound bed is viable, pink or red, moist, and may also present as an intact or ruptured serum-filled blister. Adipose (fat) is not visible and deeper tissues are not visible. Granulation tissue, slough and eschar are not present.

Stage 3 Pressure Injury: Full-thickness skin loss Full-thickness loss of skin, in which adipose (fat) is visible in the ulcer and granulation tissue and epibole (rolled wound edges) are often present. Slough and/or eschar may be visible. The depth of tissue damage varies by anatomical location; areas of significant adiposity can develop deep wounds.

Stage 4 Pressure Injury: Full-thickness skin and tissue loss Full-thickness skin and tissue loss with exposed or directly palpable fascia, muscle, tendon, ligament, cartilage or bone in the ulcer. Slough and/or eschar may be visible. Epibole (rolled edges), undermining and/or tunneling often occur. Depth varies by anatomical location.

Unstageable Pressure Injury: Obscured full-thickness skin and tissue loss Full-thickness skin and tissue loss in which the extent of tissue damage within the ulcer cannot be confirmed because it is obscured by slough or eschar. If slough or eschar is removed, a Stage 3 or Stage 4 pressure injury will be revealed.

Deep Tissue Pressure Injury: Persistent non-blanchable deep red, maroon or purple discoloration Intact or non-intact skin with localized area of persistent non-blanchable deep red, maroon, purple discoloration or epidermal separation revealing a dark wound bed or blood filled blister. Pain and temperature change often precede skin color changes.

\section{RESULTS}

Pressure injuries due to respiratory support device developed in 32 (7.3\%) of 436 patients examined on the set dates during the study. Of these patients, $90.6 \%$ were male, and the mean age was $64.65 .43 .7 \%$ of them had comorbid diseases. The median value of the day of occurrence of pressure injury during the hospitalization period of the patients in the intensive care unit was found to be 6.5 days (Table 2). When the type of respiratory support received by 436 patients was examined, it was seen that $28 \%$ received treatment with low-flow oxygen, $27 \%$ with invasive mechanical ventilation, $23 \%$ with highflow oxygen, and $22 \%$ with non-invasive mechanical ventilation (Figure 1). According to the Braden Risk Assessment Scale, 25\% of these patients had medium risk and $71.8 \%$ high risk (Figure 2).

Table 2 also shows the data of the patients $(n=32)$ who developed medical device-related pressure injury. Medical devices that caused pressure injury were mask providing positive pressure ventilation $(n=13)$, intubation tube $(n=7)$, nasogastric tube $(n=5)$, nasal cannula $(n=3)$, gel pad $(n=3)$, and oxygen masks $(n=1)$.

Stage I pressure injury behind the ear due to oxygen mask was reported in 1 patient who received lowflow oxygen therapy, and deep tissue damage behind the ear was reported in 3 patients who received highflow oxygen therapy. In 13 (13.6\%) of 95 patients who received respiratory support with Noninvasive Mechanical Ventilation (NIMV), mostly deep tissue damage was detected in the upper nose and chin region due to the NIMV mask. In 15 of 116 patients (12.9\%) who received respiratory support with Invasive Mechanical Ventilation (IMV), medical device-related pressure injuries consisting of a nasogastric tube, gel pad and intubation tube were reported in various areas of the face (Figure 3). $78.12 \%$ of the injuries occurred were defined as deep tissue damage and $9.3 \%$ as unstageable stages (Table 2).

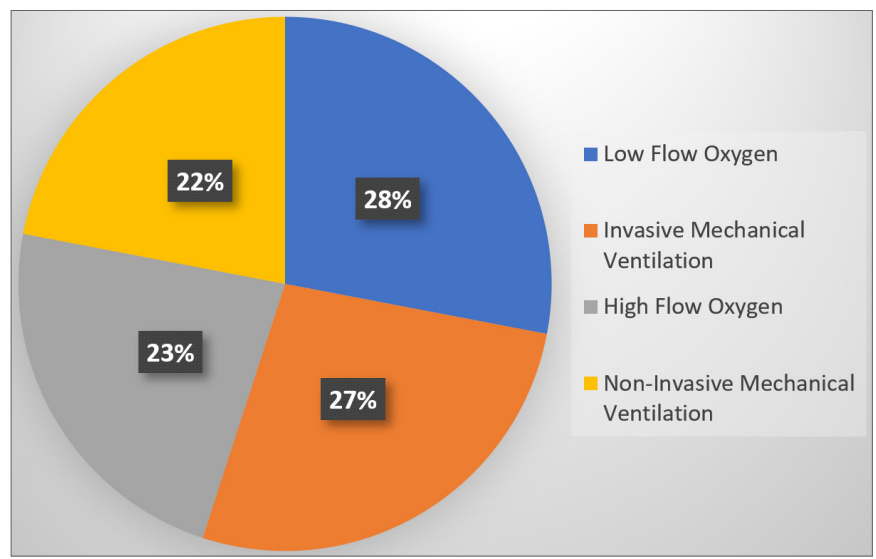

Figure 1. Ventilation support type of patients with medical devicerelated pressure injury

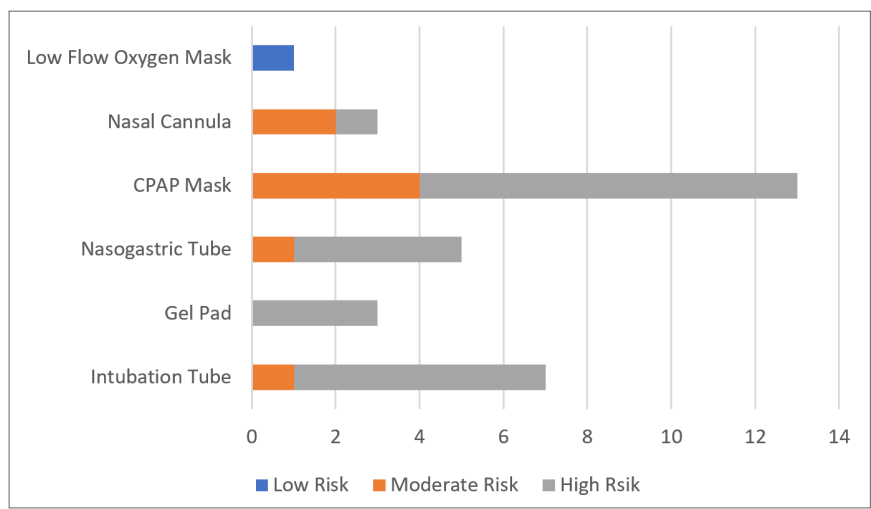

Figure 2. Medical devices that cause pressure injury according to the Braden risk level

${ }^{*}$ CPAP: Continious Positive Airway Pressure 


\begin{tabular}{|c|c|c|c|c|c|c|c|}
\hline $\begin{array}{l}\text { Ventilation } \\
\text { Support }\end{array}$ & $\begin{array}{c}\text { Medical } \\
\text { Device }\end{array}$ & $\begin{array}{l}\text { Gender } \\
\text { /Age }\end{array}$ & Comorbid & $\begin{array}{c}\text { Braden Risk } \\
\text { Level }\end{array}$ & $\begin{array}{l}\text { Occur } \\
\text { Date }\end{array}$ & $\begin{array}{c}1^{\text {st }} \text { Pressure } \\
\text { Location/Stage }\end{array}$ & $\begin{array}{c}2^{\text {nd }} \text { Pressure } \\
\text { Location/Stage }\end{array}$ \\
\hline LFOT & Mask & $\mathrm{M} / 68$ & - & Low & 3 & Behind Left Ear/ 1 & - \\
\hline \multicolumn{8}{|l|}{ HFOT } \\
\hline & Cannula & $\mathrm{M} / 57$ & - & Moderate & 10 & Behind Right Ear/ DTPI & - \\
\hline & Cannula & $\mathrm{M} / 87$ & - & Moderate & 6 & Behind Right Ear/ DTPI & Behind Left Ear/ DTPI \\
\hline & Cannula & $\mathrm{M} / 64$ & - & High & 6 & Behind Right Ear/ DTPI & Behind Left Ear/ DTPI \\
\hline \multicolumn{8}{|l|}{ NIMV } \\
\hline & Mask & $\mathrm{M} / 53$ & - & Moderate & 2 & Dorsal Nasal/DTI & - \\
\hline & Mask & $\mathrm{F} / 75$ & COPD & Moderate & 8 & Dorsal Nasal/DTPI & - \\
\hline & Mask & $\mathrm{M} / 58$ & - & Moderate & 8 & Dorsal Nasal/DTPI & - \\
\hline & Mask & $\mathrm{M} / 71$ & $\mathrm{DM}+\mathrm{HT}$ & High & 10 & Dorsal Nasal/DTPI & - \\
\hline & Mask & $\mathrm{M} / 80$ & - & High & 5 & Dorsal Nasal/DTPI & - \\
\hline & Mask & $\mathrm{M} / 50$ & - & Orta & 7 & Dorsal Nasal/DTPI & Frontale/ DTPI \\
\hline & Mask & $\mathrm{M} / 68$ & - & High & 3 & Dorsal Nasal/2 & - \\
\hline & Mask & $\mathrm{M} / 76$ & - & High & 4 & Mandibula/ DTPI & - \\
\hline & Mask & $\mathrm{M} / 49$ & - & High & 7 & Mandibula/ DTPI & - \\
\hline & Mask & $\mathrm{M} / 52$ & - & High & 5 & Mandibula/ DTPI & Upper Lip/DTPI \\
\hline & Mask & $\mathrm{M} / 53$ & $\mathrm{DM}+\mathrm{HT}$ & High & 3 & Mandibula/ DTPI & - \\
\hline & Mask & $\mathrm{F} / 42$ & $\mathrm{DM}$ & High & 7 & Mandibula/ DTPI & - \\
\hline & Mask & $\mathrm{M} / 77$ & $\mathrm{DM}$ & High & 9 & Mandibula/ EE & - \\
\hline \multicolumn{8}{|l|}{ IMV } \\
\hline & NGT & $\mathrm{M} / 78$ & HT & High & 8 & Dorsal Nasal/DTPI & - \\
\hline & NGT & $\mathrm{M} / 77$ & $\mathrm{DM}$ & High & 4 & Dorsal Nasal/DTPI & - \\
\hline & NGT & $\mathrm{M} / 84$ & & High & 5 & Dorsal Nasal/DTPI & - \\
\hline & NGT & $\mathrm{F} / 80$ & Arrhythmia & Moderate & 3 & Dorsal Nasal/2 & - \\
\hline & NGT & $\mathrm{M} / 85$ & $\mathrm{DM}$ & High & 3 & Dorsal Nasal/2 & - \\
\hline & Gel Pad & $\mathrm{M} / 67$ & $\mathrm{DM}$ & High & 20 & Frontale/ DTPI & - \\
\hline & Gel Pad & $\mathrm{M} / 60$ & HT/CKD & High & 6 & Frontale/ DTPI & - \\
\hline & Gel Pad & $\mathrm{M} / 62$ & - & High & 6 & Frontale/ DTPI & - \\
\hline & IT & $\mathrm{M} / 68$ & CAD & High & 5 & Right Maxilla/ DTPI & Left Maxilla/DTPI \\
\hline & IT & $\mathrm{M} / 30$ & & Moderate & 4 & Lower Lip/ DTPI & - \\
\hline & IT & $\mathrm{M} / 61$ & $\mathrm{DM}$ & High & 9 & Left Maxilla/ DTPI & Right Maxilla/DTPI \\
\hline & IT & $\mathrm{M} / 44$ & - & High & 8 & Mandibula/ EE & - \\
\hline & IT & $\mathrm{M} / 64$ & - & High & 14 & Mandibula/ EE & Upper Lip/ DTPI \\
\hline & IT & $\mathrm{M} / 59$ & $\mathrm{HT}+\mathrm{MI}$ & High & 4 & Mandibula/ DTPI & Frontale/ DTPI \\
\hline & IT & $\mathrm{M} / 70$ & - & High & 6 & Mandibula/DTPI & - \\
\hline
\end{tabular}

\section{DISCUSSION}

Acute respiratory failure syndrome is a common complication due to COVID-19 infection (18) and has thus led to an increase in the number of patients needing respiratory support in intensive care units, resulting in most of these patients receiving respiratory support with low/high flow oxygen therapy or invasive/noninvasive mechanical ventilation (19-21). Although the exact data are not yet available, it is known that the increase in the need for respiratory devices and the prone position given to increase oxygenation has caused a significant increase in the incidence of medical device-related pressure injury $(2,12)$.
In our study, the prevalence of medical device-related pressure injury in 436 patients treated in the intensive care unit with the diagnosis of COVID-19 disease, which we examined over a 12-month period, was determined as $7.36 \%(\mathrm{n}=32)$. The most common devices causing pressure injuries were positive pressure ventilation masks (40.6\%) and intubation tubes (21.8\%). Kayser et al. (22) reported the prevalence of medical device-related pressure injury as $0.6 \%(\mathrm{n}=601)$ with the most common devices causing them being nasal cannula $(26 \%)$ and masks providing positive pressure ventilation (9\%), respectively. In an 11-month prevalence study conducted by Arnold-Long et al. (23), 47\% ( $\mathrm{n}=142)$ of the patients 
developed medical device-related pressure injury, and the most common devices causing this were respiratory devices, intubation tubes, splints and fixations, respectively. In a study by Jackson et al. (24) in which the authors systematically compiled the data of twenty-nine studies (17 cross-sectional studies and 12 cohort studies) including data on 126.150 patients, the mean prevalence of medical device-related pressure injury was $10 \%$. The most common medical devices causing these injuries were devices providing respiratory support, neck collars, tube connection cables, splints and intravenous catheters (25). The studies in the literature on medical devicesrelated pressure injuries seem to have limitations and differences. This may be because some nurses working in different institutions do not have sufficient knowledge about the terminology of the National Pressure Injury Advisory Panel (NPIAP) or do not agree with NPIAP about staging (17). The differences between pressure injury risk assessment scales may also be another reason. For example, the Glamorgan Scale, which is specific to pediatric patients, considers medical devices as pressure injury risk, whereas many of the commonly used scales to evaluate pressure injury risks in adults (e.g., Braden, Waterlow, etc.) disregard these devices (25). The prevalence determined in our study, i.e. $7.36 \%$, seems to be below the average values compared to the literature. This may be due to the individual characteristics of the patients, the differences in the health care services they receive, and the fact that our sample consisted of patients who developed medical device-related pressure injury providing only respiratory support.

Of the 32 patients, $90.6 \%$ of whom were male, and the mean age was 64.64, who developed medical devicerelated pressure injury in the study, $43.7 \%$ had a history of comorbidity and a significant majority of these patients had high Braden Risk Scale scores. The study of Ibara et al. (26) evaluating pressure injuries due to prone position during the COVID-19 pandemic emphasized that the majority of patients who developed such injuries due to medical devices (72\%) were male patients. In that study, the mean age of the evaluated patients was 61 and all had very high Braden Risk Scale scores (26). In another similar study conducted by Sleiwah et al. (18), the majority of the patients were male $(87 \%)$, and the mean age was 58.6. In the study of Martel and Orgill (2), the majority of patients who developed medical devicerelated pressure injury were also male. Girard et al. (27) reported that being male and 60 years of age and older increased the risk of pressure injury in a study they conducted to evaluate the effect of the position given to the patient on pressure injury in patients with acute respiratory failure. Most patients treated in intensive care units are at high risk of developing pressure injury due to insufficient tissue perfusion, being sedated and restricted in their ability to move, as well as having a history of comorbidities. Added to these factors, the use of medical devices further increases the risk of medical devicerelated pressure injury, and among the devastating effects of COVID-19, cytokine release syndrome and cytokine storm, endothelial dysfunction and ischemia accelerate the pressure injury process $(2,18,28)$. Determining the age, gender, comorbidities, and most importantly, the risk level of medical device-related pressure injury in the care of patients receiving respiratory support and meeting their care needs by taking into consideration the risk factors can be deemed a prerequisite to prevent the development of pressure injuries, including pressure injuries, due to medical devices.

In our study, when the findings related to the areas where pressure injuries developed due to medical devices were examined, it was observed that pressure injuries developed mostly on the nose (37.5\%) and chin $(31.25 \%)$. Among the pressure injury stages, deep tissue damage was found to have the highest prevalence. In the study of Ibarra et al. (26), the cheek (18\%), upper nose $(18 \%)$ and chin (16\%) were the most affected areas, and the prevalence of Stage 2 pressure injury was the highest (64\%), followed by Stage 1 pressure injury. In the study of Sleiwah et al. (18), the prevalence of medical devicerelated pressure injury was most common around the mouth and the prevalence of stage 2 pressure injuries was the highest, followed by stage 3 and unstaged pressure injuries. We believe that the more common prevalence of deep tissue damage and unstaged pressure injury in medical device-related pressure injury in our study compared to previous studies may be related to the prone positioning of the majority of patients for a long time in order to increase oxygenation for the management of severe acute respiratory failure and the increase in the pressure applied by the medical devices to the tissue. We also believe that the difficulty of working with protective equipment during the COVID-19 pandemic process, the insufficient number of nurses and lack of training, the fact that the newly assigned nurses in the intensive care units do not have sufficient knowledge about medical device-related pressure injury may be related to these findings of our study (27-29). Current international guidelines recommend that comprehensive evaluation of skin tissue under a medical device be performed regularly and documented in the patient's medical record $(1,3,10$ 12). Evaluation of the tissue involves moving the device in place to dissipate the pressure the tissue is exposed to. According to Sleiwah et al. (5), failure to choose the appropriately sized safety bands for the patient causes pressure injury. It is therefore imperative to apply the device correctly and choose the right size for the patient. In addition, we are of the opinion that the use of pressure sensors that will give warning signals in the application of 
medical devices will be an effective method in preventing medical device-related pressure injury, especially during the COVID-19 pandemic, where workforce management is very important (5).

\section{CONCLUSION}

In our study, potential factors that may have caused the incidence of medical device-related pressure injury specific to COVID-19 disease include the rapid increase in the need for respiratory support, the ischemia caused by this infection, and the use of prone position. On the other hand, it can be said that the reasons such as lack of personnel against the increase in the demand for intensive care units, lack of education about pressure injury, limitations in accessing wound care materials, difficulties in the working environment under pandemic conditions may have increased the risk of pressure injury caused by medical devices.

\section{ETHICAL DECLARATIONS}

Ethics Committee Approval: The study was carried out with the permission of University of Health Sciences, Hamidiye Clinical Researchs Ethics Committee (Date: 22.03.2021, Decision No: 21717).

Informed Consent: Because the study was designed retrospectively, no written informed consent form was obtained from patients.

Referee Evaluation Process: Externally peer-reviewed.

Conflict of Interest Statement: The author has no conflicts of interest to declare.

Financial Disclosure: The author declared that this study has received no financial support.

Author Contributions: The author declare that they have all participated in the design, execution, and analysis of the paper, and that they have approved the final version.

\section{REFERENCES}

1. National Pressure Injury Advisory Panel (NPIAP). Medical Device Related Pressure Injury (MDRPI) Prevention--What's the Evidence? 2018. Available from: https://npiap.com/store/ ViewProduct.aspx?id=14128515 Acess date: 30 October 2021.

2. Martel T, Orgill DP. Medical device-related pressure injuries during the COVID-19 pandemic. J Wound Ostomy Continence Nurs 2020; 47: 430-4.

3. National Pressure Ulcer Advisory Panel (NPUAP). European Pressure Ulcer Advisory Panel and Pan Pacific Pressure Injury Alliance 2014: Prevention and treatment of pressure ulcers: Quick reference guide. 2014. Available from: https://www.npuap. org/wp-content/uploads/2014/08/Updated-10-16-14-QuickReference-Guide-DIGITAL-NPUAP-EPUAP-PPPIA-16Oct 2014. pdf Access date: 10 October 2021.

4. Bryant RA, Nix DP. Developing and maintaining a pressure ulcer prevention program. In: Acute and Chronic Wounds: Current Management Concepts. 4rd ed. St Louis, MO: Elsevier; 2012; 137 53.
5. Haugen V. Prevention of pressure ulcers due to medical devices. Perspect 2015; 1-11.

6. Black JM., Kalowes P. Medical device-related pressure ulcers. Chronic Wound Care Management and Research 2016; 3: 91-9.

7. The Joint Commission, Division of Healthcare Improvement. Quick safety, managing medical device-related pressure injuries. 2018. Available from: https://www.jointcommission. org/ resources /new-and-multimedia/newsletters/newsletters/ quick-safety/quick-safety-43-managing-medical-devicerelatedpressure-injuries. Access date: 18 January 2021.

8. Ramondetta A, Ribero S, Costi S, Dapavo P. Pression-induced facial ulcers by pron position for COVID-19 mechanical ventilation. Dermatol Ther 2020; 33.

9. Petrilli CM, Jones SA, Yang J, et al. Factors associated with hospital admission and critical illness among 5279 people with coronavirus disease 2019 in New York City: Prospective cohort study. BMJ 2020; 369.

10.European Pressure Ulcer Advisory Panel (EPUAP). COVID 19 and pressure ulcer prevention forum public group. COVID 19 and Pressure Ulcer Prevention Forum. 2020. Available from: https://www.facebook.com/groups/3285977198294372. Access date: 18 June 2021.

11. Wound Ostomy and Continence Nursing Society (WOCN). COVID-19 resources, 2020. Available from: https://www.wocn. org/page/COVID19. Access date: 18 June 2021.

12.Cuddigan J. National Pressure Injury Advisory Panel. NPIAP COVID-19 resources, 2020. Available from: https://npiap.com/ news/499328/NPIAP-COVID-19-Resources-.htm. Access date: 18 June 2021.

13. Raoof S, Nava S, Carpati C, Hill NS. How I do it: high flow, non-invasive ventilation and awake (non-intubation) proning in COVID-19 patients with respiratory failure. Chest 2020; 158: 1992-2002.

14. Singh C, Tay J, Shoqirat N. Skin and mucosal damage in patients diagnosed with COVID-19: A case report. J Wound Ostomy Continence Nurs 2020; 47: 435-8.

15. Pınar R, Oğuz S. Norton ve Braden bası yarası değerlendirme ölçeklerinin yatağa bağımlı aynı hasta grubunda güvenirlik ve geçerliğinin sınanması: uluslararası katılımlı VI. Ulusal Hemşirelik Kongresi, Kongre Kitabı, Ankara, 1998; 172-5.

16. Bergstrom N, Braden BJ, Laguzza A, Holman V. The Braden scale for predicting pressure sore risk. Nursing Research 1987; 36: 20510 .

17. National Pressure Ulcer Advisory Panel. (NPUAP). Pressure Injury Stages. 2016. Available from: http://www.npuap.org/ resources/educational-and-clinical-resources/npuap-pressureinjury-stages/ Access date: 04 April 2021.

18. Sleiwah A, Nair G, Mughal M, Lancaster K, Ahmad I. Perioral pressure ulcers in patients with COVID-19 requiring invasive mechanical ventilation. Eur J Plast Surg 2020; 1-6.

19. Öztürk Durmaz S, Sümer Coşkun A, Yalçın AN. Clinical and prognostic evaluation of patients admitted to the COVID-19 pandemic unit of the emergency department. J Health Sci Med 2021; 4: 835-9.

20.Şahin Özdemirel T, Akkurt ES, Ertan Ö, Gökler ME, Akıncı Özyürek B. Complications with moderate-to-severe COVID-19 during hospital admissions in patients with pneumonia. J Health Sci Med 2021; 4: 766-71.

21.Gürün E, Akdulum İ, Akyüz M. Revealing the dilemma in COVID-19 pneumonia: use of the prone thorax CT imaging in differentiation of opacificities due to dependent zone and pneumonic consolidation. Anatolian Curr Med J 2021; 3: 78-80.

22. Kayser SA, VanGilder CA, Ayello EA, Lachenbruch C. Prevalence and analysis of medical device-related pressure injuries: Results from the international pressure ulcer prevalence survey. Advances in Skin \& Wound Care 2018; 31: 276-85. 
23. Arnold-Long M, Ayer M, Borchert K. Medical device-related pressure injuries in long-term acute care hospital setting. J Wound Ostomy Continence Nurs 2017; 44: 325-30.

24. Jackson D, Sarki AM, Betteridge R, Brooke J. Medical devicerelated pressure ulcers: A systematic review and meta-analysis. Int J Nurs Stud 2019; 92: 109-20.

25.Erbay Ö, Ceylan İ, Kelebek Girgin N. A Neglected area: medical device related pressure injuries. Turkiye Klinikleri J Anest Reanim 2019; 17: 96-102.

26.Ibarra G, Rivera A, Fernandez-Ibarburu B, Lorca-García C Garcia-Ruano A. Pron position pressure sores in the COVID-19 pandemic: The Madrid experience. J Plast Reconstr Aesthet Surg 2020; 26: 1748-6815

27. Yang X, Yu Y, Xu J, et al. Clinical course and outcomes of critically ill patients with SARS-CoV-2 pneumonia in Wuhan, China: a single-centered, retrospective, observational study. Lancet Respir Med 2020; 8: 475-81.

28.Gefen A, Ousey K. Update to device-related pressure ulcers: SECURE prevention. COVID-19, face masks and skin damage. J Wound Care 2020; 29: 245-59.

29. Aydın N. COVID-19 ve palyatif bakım. J Med Palliat Care 2021; 2: 54-7. 